Original Research Article

\title{
A study to compare the efficacy of methotrexate alone vs. methotrexate plus pioglitazone in the management of plaque-type psoriasis
}

\author{
Shabeer D.*, Basavaraj Bhandare, Satyanarayana V., Pavithra Krishnan
}

\author{
Department of Pharmacology, \\ Rajarajeswari Medical College \\ and Hospital, Bangalore, \\ Karnataka, India \\ Received: 18 January 2017 \\ Accepted: 25 February 2017 \\ *Correspondence to: \\ Dr. Shabeer D., \\ Email: drshabeerd@gmail.com \\ Copyright: (C) the author(s), \\ publisher and licensee Medip \\ Academy. This is an open- \\ access article distributed under \\ the terms of the Creative \\ Commons Attribution Non- \\ Commercial License, which \\ permits unrestricted non- \\ commercial use, distribution, \\ and reproduction in any \\ medium, provided the original \\ work is properly cited.
}

\begin{abstract}
Background: Psoriasis is a common skin condition affecting a huge segment of global population. So far, the treatment has been confined to drugs like methotrexate, cyclosporine and oral retinoids which are highly toxic for long term usage and requires a novel drug that is safer.

Methods: Cases of plaque type psoriasis are divided into two arms and treated with methotrexate monotherapy in group A and methotrexate plus pioglitazone combination therapy in group B. The outcome of the study is analyzed using PASI score and DLQI scoring systems.

Results: Group A and Group B showed significant reduction in the PASI and DLQI scores. Group B was better in terms of efficacy $(p<0.05)$ when compared to Group A. There was no significant difference between the groups in terms of DLQI scoring. Both groups had similar side effect profile.

Conclusions: Pioglitazone which acts by sensitizing the cells to insulin poses no risk of hypoglycemia. It is more specific for the treatment of psoriasis as it targets the keratinocytes. Present study suggests a possible role as an adjuvant in the treatment of psoriasis, and could pave way for low dose methotrexate and thereby reducing the potential side effects.
\end{abstract}

Keywords: DLQI, Methotrexate, PASI, Pioglitazone, Plaque-type psoriasis

\section{INTRODUCTION}

Psoriasis is one of the common, chronic, inflammatory cutaneous diseases in India. ${ }^{1}$ It is characterized by aberrant differentiation and hyperproliferation of keratinocytes and inflammatory infiltration of leukocytes, predominantly into the dermis. ${ }^{2}$ It affects $2 \%$ to $3 \%$ of the world's population, with chronic plaque-type psoriasis accounting for approximately $90 \%$ of the cases. ${ }^{2}$ Prevalence of psoriasis ranges across population from $0 \%$ to $11.8 \%$ across different populations. ${ }^{3,4}$

In India, most prevalence studies are hospital based. ${ }^{5}$ Kaur et al study that included 782 patients showed a prevalence of $1.4 \%$ among the total dermatology outpatients. A similar study by Bedi et al. reported $2.8 \%$ prevalence among the dermatology OPD cases. Genetic correlation in terms of family history showed wide differences between studies. Bedi reported positive family history of psoriasis in $14 \%$ of their patients, while Kaur et al reported the same in only $2 \%$ of their patients and found that first degree relatives were affected in $84 \%$ of the cases, while second degree relatives only in $12 \%$ cases. $^{6,7}$

Currently the treatment options include the use of Methotrexate, which is an established standard; systemic drug approved by USFDA for the treatment of psoriasis. ${ }^{8}$ It acts mainly by inhibiting immune cells and is shown to be more potent in decreasing the number of lymphocytes than keratinocytes. ${ }^{9}$

Other available options are cyclosporine and oral retinoids, all of which are associated with severe toxicity and are usually an expensive ordeal in Indian scenario. There is a need for novel treatment approach with a better 
safety profile and pharmacoeconomic profile for the treatment of psoriasis. Special consideration has to be given for its long-term usage as lifelong treatment is necessary in some cases. Hence, a combination therapy using a standard, conventional agent and a non-expensive drug with additive action may be a rational approach to overcome above-mentioned limitations and at the same time increase the efficacy.

First introduced in the late 1990s, TZDs are now widely used to treat patients with type 2 diabetes. Pioglitazone hydrochloride which are peroxisome proliferatoractivated receptor (PPAR)-agonists is a Thiazolidinediones (TZD) that is used as insulin sensitizer in patients with type 2 diabetes mellitus. ${ }^{10}$ TZDs are ligands for the peroxisome proliferator activator receptor (PPAR)-c, which are expressed in many tissues, including epidermal keratinocytes.

The hallmarks of psoriasis are Inflammation, hyperproliferation, and aberrant differentiation of the keratinocytes. ${ }^{11}$ It is demonstrated that TZDs may be effective in many entities other than diabetes, including dermatologic diseases. ${ }^{12,13}$ Thiazolidinediones have been shown to inhibit keritinocyte proliferation and to induce terminal differentiation in various in vitro and murine models of psoriasis. ${ }^{14,15}$ A number of recent clinical studies have provided evidence of some therapeutic benefit of Thiazolidinediones in psoriasis. ${ }^{14,16-18}$ Further evidence in support of a role for Thiazolidinediones in the treatment of psoriasis was provided Brauchli et al who found a statistically significant decrease in the risk for the development of psoriasis in long-term users of TZDs compared with nonusers. ${ }^{19}$

Considering the fact that the effect of TZDs is largely through inhibition of epidermal cells and Methotrexate by suppression of lymphoid cells, and since psoriasis is a disease of both epidermal and lymphoid cells, there is a strong theoretical possibility that these two agents could act synergistically. Present study compares methotrexate monotherapy and pioglitazone and low dose methotrexate combination therapy in the treatment of plaque type psoriasis in an attempt to evaluate the efficacy of lower doses of MTX in the management of plaque-type psoriasis.

The rationale behind using pioglitazone (among other Thiazolidinediones) in our study was that pioglitazone is more effective in decreasing triglyceride levels than rosiglitazone, and as rosiglitazone has been withdrawn in India for its hepatotoxic potential. ${ }^{12}$ However, some of the notable adverse effects of pioglitazone may include moderate increase in hepatic transaminase levels, weight gain due to fluid retention, hematuria, and proteinuria. ${ }^{20}$ the objective of present study are:

- To compare the efficacy and safety of efficacy of methotrexate plus pioglitazone vs methotrexate alone in the management of patients with plaque-type psoriasis.

- To compare the Dermatology Life Quality Index of the patients after the treatment in both the groups.

\section{METHODS}

This prospective, randomized, comparative study of 12 weeks duration was done at the Department of Dermatology, Rajarajeswari medical college and Hospital, Bangalore, between April 2015 and July 2015.

\section{Inclusion criteria}

- Patients of both sexes were included in the study.

- Patients with chronic plaque-type psoriasis, who had indications for systemic therapy.

- Patients who are not systemically treated with medications or had undergone phototherapy for their disease in the last six months, and all topical treatments had to be withheld for at least one month before the beginning of the study.

\section{Exclusion criteria}

- Patients were not allowed to enter the study if they had a history of

Congestive heart failure,

Renal disease

Hepatic disease or Abnormal Hepatic Enzymes (Aminotransferases more than 1.5 times the upper limit of normal),

Pulmonary disease,

Diabetes, or

Any other major systemic diseases.

- Women of child-bearing potential were excluded.

- Patients were withdrawn if

There was severe weight gain due to fluid retention and edema in the follow up.

A significant change in blood cell count.

A significant increase in hepatic enzymes (more than 2.5 times of the baseline).

Nausea and vomiting unresponsive to symptomatic treatment, or

Any persistent change in blood biochemistry results and urinalysis (e.g., hematuria or proteinuria).

\section{Pretreatment evaluation}

A complete physical examination was performed and psoriasis area and severity index (PASI) scores were calculated in all patients. The quality of life was assessed by the dermatology life quality index (DLQI) questionnaire.

All patients underwent laboratory investigations like complete blood cell count, random blood glucose, lipid profile, renal and liver function tests, and urinalysis were also performed. 


\section{Treatments and follow-up}

Subjects were randomized to either the Methotrexate group (group A) or Methotrexate plus pioglitazone group (group B). In both groups oral Methotrexate was initiated at a dose of $7.5 \mathrm{mg}$ weekly and titrated to a maximum dose of $10,12.5$, or $15 \mathrm{mg}$ for patients with a body mass index (BMI) of <30, 30-35 and > 35, respectively, by adding $2.5 \mathrm{mg}$ weekly at intervals of $1-2$ weeks duration.

To prevent the adverse effects of Methotrexate, folic acid $1 \mathrm{mg}$ was administered daily for all patients, except the days they were receiving Methotrexate. Dosage of Methotrexate was divided into $2.5-5.0 \mathrm{mg}$ at 12-hour intervals for three doses each week. Patients in group B also received pioglitazone $30 \mathrm{mg} /$ day given orally in addition to the methotrexate therapy.

Duration of the study period was based on the observation that maximum effect of pioglitazone may emerge after several weeks. Study period was fixed as 12 weeks. Subjects were followed at weeks 1, 2, 4, 6, 10, and 12 after the start of the study. During the study period, no concurrent antipsoriatic drug (topical or systemic) was allowed. Emollients were allowed whenever necessary.

\section{Efficacy and safety assessments}

PASI and DLQI scores reassessed at 6, 10, and 12 weeks after baseline for efficacy measurements. The primary efficacy outcome parameter was PASI score change between the study groups at the end of study (week 12) relative to baseline (week 0 ).

The secondary efficacy outcome measure was the DLQI score change between the two groups at the end of week 12 relative to baseline. During each visit, patients were evaluated for adverse effects by taking detailed history, weight monitoring, direct questions about side effects, and laboratory investigations. PASI 75 was used as an additional measure to check the efficacy of the treatment groups, where $75 \%$ reduction in PASI score was achieved.

\section{Statistical analysis}

Subjects were assigned in two parallel groups by randomization. Statistical differences of efficacy between groups were calculated using the Mann-Whitney U test for continuous variables and Fisher exact test was used for categorical variables, with statistical significance at $p$ $<0.05$. Data will be analyzed by SPSS software (version 13.0; SPSS, Chicago, IL, USA).

\section{RESULTS}

The total study enrollment was 34 patients (17 cases randomly assigned to each group) ranging in age from 18 to 75 years, all with plaque-type psoriasis. Of these 22 ,
$(64.7 \%)$ were males and $12(35.3 \%)$ were females. The MTX treatment group $(n=17)$ and the MTX plus pioglitazone group $(n=17)$ were comparable at baseline, in terms of demographics and disease characteristics.

Table 1: Baseline demographic details and disease characteristics.

\begin{tabular}{|lll|}
\hline & $\begin{array}{l}\text { Methotrexate } \\
\text { alone } \\
\text { group }\end{array}$ & $\begin{array}{l}\text { Methotrexate + } \\
\text { pioglitazone } \\
\text { group }\end{array}$ \\
\hline No. of patients & 17 & 17 \\
\hline $\begin{array}{l}\text { Age (years) } \\
\text { mean } \pm \text { SD }\end{array}$ & $48.6 \pm 5.76$ & $42.4 \pm 7.9$ \\
\hline $\begin{array}{l}\text { Sex } \\
\text { (male/female) }\end{array}$ & $12 / 5$ & $10 / 7$ \\
\hline Weight kg (mean) & 70.6 & 68.4 \\
\hline $\begin{array}{l}\text { PASI baseline } \\
\text { mean }\end{array}$ & 7.84 & 8.02 \\
\hline
\end{tabular}

*there was no significant difference between the groups at baseline $(\mathrm{p}>0.05)$.

The difference in the mean PASI scores between the groups was statistically significant at week $12(\mathrm{P}=0.021)$ with $67.58 \%$ reduction in group B mean PASI scores as compared with a $56.63 \%$ reduction in group A. 8 patients $(18.2 \%)$ in group B achieved PASI 75 by week 12, while 5 patients in group A obtained a PASI 75 at the same interval, which was significant $(\mathrm{P}<0.001)$.

Table 2: Psoriasis area and severity index (PASI) score at baseline and at end of study.

\begin{tabular}{|lll|}
\hline & Group A & Group B \\
\hline 0 week & 7.84 & 8.02 \\
\hline 12 weeks & 3.4 & 2.6 \\
\hline \% reduction PASI & $56.63^{*}$ & $67.58^{*}$ \\
\hline
\end{tabular}

${ }^{*} \mathrm{P}<0.05$ when compared 12 week scores with the baseline. There was also a significant difference $(p<0.05)$ seen between the groups with respect to treatment outcome.

The efficacy of treatment was also evaluated by theDLQI score using the relevant questionnaire.

Table 3: Dermatology life quality index (DLQI) score at baseline and at end of study.

\begin{tabular}{|lll|}
\hline & Group A & Group B \\
\hline 0 week & 18 & 20.4 \\
\hline 12 weeks & 10.3 & 10 \\
\hline \% reduction DLQI & $42.7^{*}$ & $50.98^{*}$ \\
\hline
\end{tabular}

At 12 weeks from the baseline, a $50.98 \%$ decrease in the mean DLQI score was seen in of group B, while the decrease for group A was $42.7 \%$. Which was although a significant improvement at 12 weeks from the baseline was not statistically significant $(\mathrm{P}=0.708)$ when intergroup comparison was performed. It is notable that all percentages have been calculated relative to baseline. 
Table 4: Adverse events during the study period.

\begin{tabular}{|lll|}
\hline & $\begin{array}{l}\text { Methotrexate } \\
\text { alone group } \\
(\mathbf{n}=\mathbf{1 7})(\%)\end{array}$ & $\begin{array}{l}\text { Methotrexate } \\
\text { + pioglitazone } \\
\text { group }(\mathbf{n}=17) \\
(\%)\end{array}$ \\
\hline Total AEs & $3(17.65)$ & $3(17.65)$ \\
\hline Weakness/fatigue & $0(0)$ & $1(5.8)$ \\
\hline Nausea/vomiting & $2(11.74)$ & $1(5.8)$ \\
\hline Headache & $1(5.8)$ & $0(0)$ \\
\hline $\begin{array}{l}\text { Elevated liver } \\
\text { enzymes (less than } \\
\begin{array}{l}1.5 \text { times the } \\
\text { normal level })\end{array}\end{array}$ & $0(0)$ & $1(5.8)$ \\
\hline
\end{tabular}

\section{DISCUSSION}

We conducted this 12-week, single-center, randomized study to evaluate the effects of a combination of methotreaxate and pioglitazone in the management of plaque-type psoriasis.

17 patients were included in each group, of which Group A had 12 males 5 females, Group B 10 males and 7 females. $64.7 \%$ of the cases were male and $35.3 \%$ were females. Mean age group of group A was 48.6 years and 42.4 years. These estimates are similar to a study by kaur et al. where it was found that $67 \%$ were men and $33 \%$ were women, male to female ratio being $2.03: 1$. Women had slightly lower mean age of onset (27.6 years) compared to the men (30.9 years). ${ }^{7}$

According to our study results, both the groups had significant improvement from their baselines in terms of PASI score and DLQI scoring. The percentage reduction found in our study is similar to a study by Lajevardi et al. ${ }^{22}$ The combination therapy proved to be significantly better than the methotrexate monotherapy in reducing the PASI score. However, DLQI scoring showed no significant difference between the groups.

Subjects were closely monitored for; adverse effects if any were noted. Laboratory tests and weight measurement were done as per the proforma. Although adverse events occurred in 6 patients they were temporary and mild in severity, with the overall frequency of them similar across treatment groups. The incidence of adverse effect was less as compared to a previous study. ${ }^{21}$ Our study had two important advantages. It had a longer duration in comparison with previous studies considering the effect of pioglitazone on plaque-type psoriasis.

It was also a randomized controlled study to evaluate the influence of pioglitazone on DLQI scores of patients with psoriasis. Our study also had some limitations. The female participants were outnumbered by males, because we excluded all women with child-bearing potential. It also was not a placebo-controlled study.

\section{CONCLUSION}

In conclusion, treatment with combination therapy of methotrexate with pioglitazone proved superior as compared to methotrexate monotherapy in patients with plaque-type psoriasis.

No significant difference between the groups was found in the intergroup analysis for DLQI. Moreover, we observed that the combination therapy showed better results in disease improvement with a lower dose of MTX, thereby reducing the risk of serious adverse events experienced by higher doses of MTX.

Nevertheless, studies on the subject are yet scarce, and to further establish pioglitazone as a possible treatment optionlarge, placebo controlled trials of longer duration are needed.

Funding: No funding sources

Conflict of interest: None declared

Ethical approval: The study was approved by the Institutional Ethics Committee

\section{REFERENCES}

1. Menter A, Gottlieb CA, Feldman SR, Voorhees ASV, Leonardi CL, Gordon KB, et al. Guidelines of care for the management of psoriasis and psoriatic arthritis. J Am Acad Dermatol. 2008;58(5):826-50.

2. Griffiths CE, Barker JN. Pathogenesis and clinical features of psoriasis. Lancet. 2007;370:263-71.

3. Farber EM, Nall L. Epidemiology: natural history and genetics. In: Roenigk Jr HH, Maibach HI, editors. Psoriasis. New York: Dekker; 1998:107-57.

4. Swanbeck G, Inerot A, Martinsson T, Wahlstrpm J. A population genetic study of psoriasis. $\mathrm{Br} \mathrm{J}$ Dermatol. 1994;131:32-9.

5. Kaur I, Kumar B, Sharma VK, Kaur S. Epidemiology of psoriasis in a clinic from North India. Indian $\mathbf{J}$ Dermatol Venereol Leprol. 1986;52:208-12.

6. Bedi TR. Clinical profile of psoriasis in North India. Indian J Dermatol Venereol Leprol. 1995;61:202-5.

7. Kaur I, Handa S, Kumar B. Natural history of psoriasis: a study from the Indian subcontinent. J Dermatol. 1997;24:230-4

8. Magdalena CO, Anna SP. The possibilities and principles of methotrexate treatment of psoriasis - the updated knowledge. Post epy Dermatol Alergol. 2014;31(6):392-400.

9. Jeffes EWB, McCullough JL, Pittelkow MR, McCormick A, Almanzor J, Liu G. Methotrexate therapy of psoriasis: differential sensitivity of proliferating lymphoid and epithelial cells to the cytotoxic and growth-inhibitory effects of methotrexate. J Invest Dermatol. 1995;104:183-4.

10. Kuenzli S, Saurat JH. Peroxisome proliferatoractivated receptors in cutaneous biology. $\mathrm{Br} \mathrm{J}$ Dermatol. 2003;149:229-36. 
11. Lima H, Dogan S, Atakan N, Lima HC, Fallen RS, Mitra A, Morrissey L et al. Psoriasis - Types, Causes and Medication. Published by InTech Janeza Trdine 9, 51000 Rijeka. Croatia . 2013

12. Boyd AS. Thiazolidinediones in dermatology. Int $\mathbf{J}$ Dermatol. 2007;46:557-63.

13. Friedmann PS, Cooper HL, Healy E. Peroxisome proliferator-activated receptors and their relevance to dermatology. Acta Derm Venereol, 2005;85:194-202.

14. Ellis CN, Varani J, Fisher GJ. Troglitazone improves psoriasis and normal izes models of proliferative skin disease: ligands for peroxisome proliferators activated receptor-gamma inhibit keratinocytes proliferation. Arch Dermatol. 2000;136(5):609-16.

15. Demerjian M, Man MQ, Choi EH. Topical treatment with thiazolidinediones, activators of peroxisome proliferator-activated receptor-gamma, normalizes epidermal homeostasis in a murine hyperproliferative disease model. Exp Dermatol. 2006;15(3):154-60.

16. Pershadsingh HA, Sproul JA, Benjamin E, Finnegan J, Amin NM. Treatment of psoriasis with troglitazone therapy. Arch Dermatol. 1998;134(10):1304-5.

17. Robertshaw H, Friedmann PS. Pioglitazone: a promising therapy for psoriasis. $\mathrm{Br} \mathrm{J}$ Dermatol. 2005;152(1):189-91.
18. Shafiq N, Malhotra S, Pandhi P. Pilot trial: pioglitazone versus placebo in patients with plaque psoriasis (the P6). Int J Dermatol. 2005;44(4):328-33.

19. Brauchli YB, Jick SS, Curtin F, Meier CR. Association between use of thiazolidinediones or other oral antidiabetics and psoriasis: a population based casecontrol study. J Am Acad Dermatol. 2008;58(3):421-9.

20. Jermendy G. PPARg agonists-Antidiabetic drugs with a potential role in the treatment of diseases other than diabetes. Diabetes Res Clin Pract. 2007;78S:S29-39.

21. Lajevardi V, Hallaji Z, Daklan S, Abedini R, Goodarzi A, Abdolreza M. The efficacy of methotrexate plus pioglitazone vs. methotrexate alone in the management of patients with plaque-type psoriasis: a single-blinded randomized controlled trial. Int J Dermatol. 2015;54(1):95-101.

Cite this article as: Shabeer D, Bhandare B, Satyanarayana V, Krishnan P. A study to compare the efficacy of methotrexate alone vs. methotrexate plus pioglitazone in the management of plaque-type psoriasis. Int J Basic Clin Pharmacol 2017;6:859-63. 